\title{
Children's Daily Activities and Well-being during the COVID-19 Lockdown: Associations with Child and Family Characteristics
}

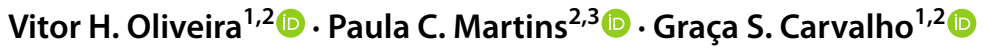 \\ Accepted: 20 January 2022 \\ (c) The Author(s), under exclusive licence to Springer Science+Business Media, LLC, part of Springer Nature 2022
}

\begin{abstract}
Learning, leisure, social, and movement activities are essential facets of children's development affecting their physical, mental, and social well-being. During the first Covid-19 lockdown and post-lockdown period, children's everyday lives were disrupted and altered in significant ways for an extended period, raising several concerns regarding its negative effects. This study investigated children's daily activities during the lockdown and post-lockdown period, considering child and family factors that influenced their participation, and the effects of daily activities on child well-being. Cross-sectional data were collected during June and July 2020 from a sample of $3^{\text {rd }}$ and $4^{\text {th }}$ graders $(n=110)$ and their parents. Participants reported the intensity of children's weekly participation in various learning, leisure, socializing, and movement activities, child and family characteristics, and child well-being outcomes. Findings indicate an overall pattern characterized by a higher prevalence of sedentary behaviors (screen time) and a lower prevalence of active leisure and playing activities, particularly among socioeconomically vulnerable children. Compared to boys, girls were less physically active but engaged more in play and social activities. In addition, sleep, active leisure, playing and learning activities, and family coping strategies were linked to better overall child well-being. These findings help identify promising avenues for effective intervention strategies, at the family and community levels, aimed at promoting child well-being and mitigating harm during the present and future crises.
\end{abstract}

Keywords Covid- $19 \cdot$ Child health $\cdot$ Family adaptation $\cdot$ Health promotion $\cdot$ Time use

During the Covid-19 first lockdown and post-lockdown period, children's everyday lives were disrupted. In a context of economic downturn, social isolation, and widespread uncertainty, families were given the responsibility to care for their children at home, full-time, and during an extended period, regardless of their resources and needs (Cheng et al., 2020; Cluver et al., 2020; Fore, 2020; Prime et al., 2020). Prolonged confinement at home coupled with lower access to educational, social, and health services has raised several concerns amongst non-governmental organizations, academics, professionals, and policymakers, regarding the possible adverse effects on child well-being and development,

Vitor H. Oliveira

vhpo@ outlook.com

1 Institute of Education, University of Minho, Campus de Gualtar, Braga, Portugal

2 CIEC-UM Research Centre on Child Studies, University of Minho, Campus de Gualtar, Braga, Portugal

3 School of Psychology, University of Minho, Campus de Gualtar, Braga, Portugal both short- and long-term (Bates et al., 2020; Fore, 2020; Wang et al., 2020). It is expected that these sharp changes in children's environments and routines have had a significant impact on well-being, affecting particularly those experiencing vulnerabilities and those who lost access to their support systems, thus contributing to the increase of pre-existing inequalities (Cheng et al., 2020; Patrick et al., 2020; United Nations, 2020). However, the knowledge about children's everyday lives during the lockdown, its impacts on child well-being, and its influencing factors is still emerging (Bates et al., 2020; Guan et al., 2020; Larsen et al., 2021).

As a result of the implementation of pandemic mitigation efforts by governments - home confinement, social isolation, the closing of schools and non-essential services -, children's daily activity patterns and routines were altered in significant ways. In Portugal, during the first lockdown and post-lockdown period from the middle of March 2020 to the end of the school year in the middle of June 2020, schoolaged children stayed at home. Consequently, using a homebased distance-learning model, the Portuguese Ministry of Education has implemented a national program via televised 
lessons for students which were complemented by teachers' tutoring on digital platforms. In addition to the fact that everyday life was now spent at home, children lost access to daily activities such as classes at school, playing with friends, extracurricular and enrichment activities, sports, among other important leisure and socialization experiences with peers and adults. These new routines presented many challenges to children and their families who had to cope with feelings of loneliness, anxiety, and depression, and deal with heightened household tensions and other psychosocial stressors (e.g., reallocation of household tasks, parents working from home) related to the ongoing health and social crisis (see Larsen et al., 2021).

Daily activities occur through the routine interactions between a child and its environment (e.g., playing with a sibling, studying, hobbies, socializing with parents, watching TV, doing sports). By being developed in different ecological settings (home, school, community), frequently involving peers and adults, daily activities are the building blocks of what is experienced in the course of children's everyday life. Thus, daily activities are the essential routine tasks that children perform and engage with. These activities can be more structured (adult-supervised, goal-directed, rules-based) or less structured (informal, child-led, fewer rules), nevertheless, they constitute an important facet of child development, affecting children's physical, mental, and social well-being (Metsäpelto \& Pulkkinen, 2014; Wong et al., 2017). Both physically active behaviors (active play, sports) and sedentary behaviors (waking behaviors characterized by a low energy expenditure such as screen time) have been consistently linked with children's physical and mental health (Carson et al., 2016; Dale et al., 2019; Zhang et al., 2017). Also, stimulating leisure activities (e.g., creative leisure, extracurricular activities, dyadic/social time with parents) are known to support and enhance several child well-being outcomes (Berntsson \& Ringsberg, 2014; Oberle et al., 2019; Yogman et al., 2018). However, in the context of a health and social crisis, where children's participation in society has been severely restricted, and families' coping mechanisms have been seriously challenged, the risk for poorer physical and mental health outcomes increased (Fegert et al., 2020; Loades et al., 2020; Patrick et al., 2020; United Nations, 2020). These well-being risks may be linked to the exposure to pervasive psychosocial stressors but also an increase in sedentary behaviors, a decrease of physical activity levels, adverse changes in sleep and daily routines, as well as a lower contact with stimulating play, learning, and socialization experiences (Bates et al., 2020; Dale et al., 2019; González et al., 2020; Moore et al., 2020; Pombo et al.,2021).

Evidence on children's patterns of daily activities during the Covid-19 pandemic and its influencing factors could inform interventions, during the current pandemic and in a future crisis, aimed at protecting children's rights and well-being and preventing adverse outcomes (Fore, 2020). Therefore, the present study investigated how Portuguese school-aged children spent the first Covid-19 lockdown and post-lockdown period, considering child and family characteristics that facilitated or constrained their participation in daily activities, and examined how daily activities were linked to child well-being outcomes. Specifically, this study aimed at 1) describing the intensity of children's weekly participation in daily activities and their levels of engagement with those activities; 2) examining the differences in the intensity of weekly participation by gender, sociodemographic characteristics, and family adversity (socioeconomic change) and coping strategies (adaptation); and 3) investigating the associations between different types of daily activities and child well-being.

\section{Methods}

\section{Participants}

The present study is based on cross-sectional data from a non-probabilistic sample of 110 children enrolled in the $3^{\text {rd }}$ and $4^{\text {th }}$ grade (50\% girls), aged between 7 and 11 years old $(M=9.09, S D=0.80)$, from northern and central Portugal, and their parents (85\% mothers). Of the participating parents, $54 \%$ had an educational level up to the $12^{\text {th }}$ grade, the remaining $46 \%$ had higher education; $78 \%$ were employed full-time, $6 \%$ half-time, and the remaining $16 \%$ were unemployed, receiving training, or performing domestic work. About $83 \%$ of families were nuclear, $9 \%$ single-parent, and $8 \%$ were extended or reconstituted families.

\section{Procedures}

Participants in this study were recruited from an ongoing prospective study on children's everyday lives and healthy development. Participants were invited by email $(n=293)$, telephone $(n=41)$, and postal mail $(n=12)$, renewing the informed consent (parents) and assent (children) they had provided in an earlier stage of the global study. Then, both parents and children responded to an online survey or a paper and pencil version according to their preference $(n=$ 137 , response rate $=40 \%$ ). Incomplete research protocols $(n=27)$ were dropped, resulting in the sample previously described $(n=110)$.

From the middle of June to the end of July 2020, participants responded to the questionnaires retrospectively, as explicitly asked in the research protocol, reporting on the previous weeks of the lockdown and post-lockdown period. In Portugal, schools were closed from the $18^{\text {th }}$ of March 2020 to the end of the school year in the middle of 
June 2020. During this period, children stayed at home in their parents' care. In addition, all the questionnaires asked respondents to consider the previous months of lockdown, reinforcing the retrospective nature of the survey. The information provided by the online survey tool and by our previous experience indicates that, in total, questionnaires took approximately 35 minutes to respond to. Furthermore, the present study was guided by the legal and ethical norms in force, specifically, participation was voluntary, confidential, and anonymous, and guidance from health authorities was followed to protect the safety and well-being of participants. Finally, as described previously, the present study was conducted with a sub-sample of a larger ongoing study, which received the approval of the University's Ethics Committee and the National Ministry of Education.

\section{Measures}

\section{Children's daily activities}

A shortened version of the Q25 questionnaire (Oliveira et al., 2019) was used to assess children's participation in daily activities. Using Likert-type scales, both parents and children reported on the weekly frequency (from "never" = 0 to "daily" $=5$ ) and time spent (from "around 30 minutes" $=1$ to " 2 hours+" $=4$ ) in 11 types of daily activities, as well as the number of hours of sleep. For each activity, participants also reported the level of children's engagement with the activity (e.g., satisfaction, interest, focus) using Likertscales (from "not at all" $=0$ to "totally" $=4$ ). In the present study, two different domains of activities were considered in the analyses: the movement activities domain encompassing sleep (hours per night), physical activity (exercise, sports), active play (running outside, jumping, dancing, riding a bicycle), TV, gaming/internet, and socializing online, and the learning and socialization activities domain encompassing play (toys, games, hobbies), creative leisure (reading/ writing, drawing/painting, playing an instrument), family meals, activity with parents (parent-child joint activities), household chores, and school at home (distance-learning on television, tutoring with school-teacher, homework). A weighted score representing the intensity of weekly participation in hours was created for each daily activity by multiplying the weekly frequency by the number of hours spent (for sleep, the number of hours per night was considered). An average score for children's engagement levels across each activity domain was calculated. In preliminary validation procedures, the original Q25 has provided satisfactorily valid scores of the intensity of weekly participation of children in daily activities in terms of distribution and accuracy, with estimates in line with previous literature. In addition, differences according to child characteristics (gender, grade, chronic condition, learning disabilities) showed a good level of sensitivity of the measure. Because the instrument is constituted by ordinal/categorical items that measure the intensity of children's participation in different types of daily activities (multiple dimensions/constructs of daily life) and is not specifically measuring an underlying unidimensional construct, the Q25 short-form's intensity scores presented an overall low Cronbach's alpha of .53.

\section{Child well-being outcomes}

Children reported on their health-related quality of life using the KIDSCREEN-27 questionnaire (Ravens-Sieberer et al., 2007) consisting of 27 Likert-scales (e.g., from "never" to "always"). Three dimensions were included in the present study: a 5-item physical well-being dimension $(\alpha=.79, M=$ 2.94, $S D=0.65)$, a 7-item psychological well-being dimension $(\alpha=.86, M=3.14, S D=0.64)$, and a 7-item social well-being dimension $(\alpha=.70, M=3.25, S D=0.62)$. A score for each dimension was created by averaging the items, with a higher score representing higher levels of healthrelated quality of life. In addition, parents also reported on children's psychological adjustment using the Strengths and Difficulties Questionnaire (Goodman, 2001). A score for each internalizing $(M=3.54, S D=2.94)$, externalizing $(M=6.52, S D=3.51)$, and prosocial behavior $(M=8.87$, $S D=1.57$ ) indicator was computed by summing the corresponding 3-point items ("not true" = 0 to "very true" $=2$ ), a higher score representing higher levels of each behavior ( $\alpha=.74$ for the 25 items).

\section{Socioeconomic variables, family adversity, and family adaptation}

Parents provided information on the child's gender (coded as girls $=1$, boys $=2$ ), marital status (married/civil union $=1$, other $=2$ ), professional status (employed full-time $=$ 1 , other $=2)$, and educational level $(\leq$ high-school $=1$, higher education $=2$ ), using a sociodemographic questionnaire. Parents also reported on recent changes in the family's socioeconomic situation and routines and the family's coping behaviors during the lockdown/post-lockdown period. Using Likert-scales, parents characterized socioeconomic change using two items on parents' professional situation ("a lot worse" $=1$ to "much better" $=5$ ) and family's monthly income ("decreased a lot" $=1$ to "increased a lot" $=5)(\alpha$ $=.85 ; M=2.73, S D=0.51)$. Items were averaged and then dichotomized representing a group of families with a positive or no change in their socioeconomic situation (positive/no change $=1 ; 62 \%$ of the sample) and a group where negative change and socioeconomic adversity were experienced (negative change $=2 ; 38 \%$ ). A third item assessed daily routines change in the family ("changed completely" $=1$ to "nothing changed" $=5$ ), which was dichotomized to 
represent a group of families without alterations (no change $=1 ; 16 \%)$ and a group where alterations were experienced (change $=2 ; 84 \%$ ). The remaining four items assessed family adaptation processes and coping strategies during this period. Using from "not at all" $=1$ to "totally" $=5$, parents reported on the efforts taken to manage emotions, improve social support and communication, establish a healthy routine adjusted to the child's needs, and create opportunities for the development of new skills $(\alpha=.80 ; M=3.08, S D=$ 0.67) (see Prime, Wade, \& Browne, 2020). These items were averaged, and the measure was dichotomized by the median value representing different groups of families displaying lower $($ lower $=1,37 \%)$ and higher $($ higher $=2,63 \%$ ) levels of adaptation.

\section{Data analyses}

Descriptive statistics were calculated to describe sample characteristics and the study variables. Differences in the intensity of children's participation in daily activities according to child gender, socioeconomic characteristics (marital status, professional status, educational level), and family adversity and adaptation (socioeconomic change, daily routines change, family adaptation) were analyzed with the Mann-Whitney test (for two independent groups). The mean rank for each group, the test statistic, statistical significance, and effect size (Cohen's $d$ ) were calculated (Gignac $\&$ Szodorai, 2016). Then, due to non-normal distributions, associations between participation in daily activities, activity domain engagement, and child well-being outcomes were tested using Spearman's rank correlation coefficients. Furthermore, a bootstrapping procedure was used in inferential analyses (i.e., differences, correlations) to calculate the biascorrected accelerated (BCa) 95\% confidence intervals for $p$-values, thus indicating the precision of the estimates and allowing a more robust assessment of the null hypothesis (Ruscio, 2008). Next, child gender, socioeconomic characteristics, and family adversity and adaptation dichotomic variables were correlated with child well-being outcomes using point-biserial correlations. This step helped identify the factors that were significantly associated with child outcomes to be included as control variables in the regression models. As a result, gender, professional status, SES change, and family adaptation were selected. Next, two multivariate regression models (maximum likelihood estimation method) were used to investigate the predictive influence of daily activities per domain of activities on each child outcome, controlling for the covariates previously described. In both models, the six daily activities from the movement activities domain and the learning and socialization activities domain were entered along with the covariates, respectively. Standardized beta coefficients, standard errors, statistical significance, and variance explained $\left(R^{2}\right)$ are described. All statistical analyses were conducted on SPSS (Version 25) and AMOS (Version 25).

\section{Results}

Table 1 describes the intensity of children's participation in daily activities and the engagement levels for each type of activity and activity domain. Overall, higher intensity activities encompassed sleep, TV, gaming/internet, family meals, and school at home. Activities with lower intensity included

Table 1 Description of the Intensity of Children's Participation in Daily Activities, Engagement Levels, and 95\% Confidence Intervals

\begin{tabular}{|c|c|c|c|c|c|c|}
\hline \multirow[b]{2}{*}{ Activities } & \multicolumn{4}{|l|}{ Intensity } & \multicolumn{2}{|l|}{ Engagement } \\
\hline & min.-max.(range) & $M d n$ & $M(S D)$ & $\mathrm{BCa} 95 \% \mathrm{CI}$ & $M(S D)$ & $\mathrm{BCa} 95 \% \mathrm{CI}$ \\
\hline \multicolumn{7}{|l|}{ Movement } \\
\hline sleep $^{\text {a }}$ & $8-10(2)$ & 9.00 & $9.03(0.60)$ & {$[8.92,9.13]$} & $2.33(1.08)$ & {$[2.11,2.54]$} \\
\hline physical activity & $0-10(10)$ & 3.00 & $3.50(2.46)$ & {$[3.05,4.00]$} & $3.04(0.85)$ & {$[2.87,3.22]$} \\
\hline active play & $0-14(14)$ & 3.50 & $5.19(4.65)$ & {$[4.32,6.13]$} & $3.29(0.64)$ & {$[3.17,3.41]$} \\
\hline$T V$ & $0.25-14(13.75)$ & 10.50 & $9.14(3.85)$ & {$[8.37,9.88]$} & $3.14(0.68)$ & {$[3.01,3.27]$} \\
\hline gaming/internet & $0.25-14(13.75)$ & 7.00 & $7.93(4.23)$ & {$[7.07,8.81]$} & $3.27(0.72)$ & {$[3.13,3.39]$} \\
\hline socializing online & $0-14(14)$ & 2.50 & $3.64(3.80)$ & {$[2.89,4.37]$} & $2.93(0.78)$ & {$[2.78,3.08]$} \\
\hline domain level & & & & & $3.00(0.44)$ & {$[2.92,3.08]$} \\
\hline \multicolumn{7}{|c|}{ Learning and socialization } \\
\hline play & $0-14(14)$ & 1.88 & $3.13(3.59)$ & {$[2.49,3.84]$} & $2.74(0.66)$ & {$[2.62,2.87]$} \\
\hline creative leisure & $0-14(14)$ & 2.50 & $3.57(3.39)$ & {$[2.86,4.27]$} & $2.52(0.85)$ & {$[2.35,2.69]$} \\
\hline family meals & $2.5-14(11.5)$ & 7.00 & $7.13(2.77)$ & {$[6.64,7.65]$} & $3.14(0.74)$ & {$[3.00,3.29]$} \\
\hline activity $w /$ parents & $0.25-14(13.75)$ & 3.75 & $6.53(4.54)$ & {$[5.56,7.49]$} & $2.78(0.68)$ & {$[2.66,2.90]$} \\
\hline household chores & $0-14(14)$ & 3.50 & $3.56(2.75)$ & {$[3.06,4.15]$} & $2.14(0.94)$ & {$[1.94,2.32]$} \\
\hline school at home & $4-25(21)$ & 15.00 & $16.30(5.41)$ & {$[15.31,17.35]$} & $2.34(0.82)$ & {$[2.19,2.48]$} \\
\hline domain level & & & & & $2.60(0.53)$ & {$[2.50,2.69]$} \\
\hline
\end{tabular}

${ }^{\mathrm{a}}$ hours of sleep per night; $\mathrm{BCa}=$ bias-corrected accelerated. 
physical activity, active play, socializing online, play, creative leisure, activity with parents, and household chores. In addition, the activities with higher child engagement levels were physical activity, active play, gaming/internet, $T V$, and family meals. At the domain level, movement activities showed higher child engagement compared with learning and socialization activities. Statistically significant associations were found among daily activities (see Table 2).

The differences in the intensity of children's participation in movement activities (Table 3 ) and learning and socialization activities (Table 4) according to gender, socioeconomic characteristics, and family adversity (daily routines and socioeconomic change) and adaptation are described. Both statistically significant results and effects sizes were considered in the analysis of these differences, as defined by Gignac and Szodorai (2016). Gender differences indicated that girls spent more time in activities such as watching $T V$, socializing online, play, creative leisure, and activity with parents whereas boys spent more time in physical activity and active play. Differences according to socioeconomic characteristics indicated that children from single-parent families spent more time in activities such as physical activity, active play, socializing online, family meals, activity with parents, and household chores, while children whose parents were married/civil union participated more in activities such as school at home and watching $T V$. In addition, children whose parents were employed full-time showed higher levels of participation in physical activity, active play, socializing online, and activity with parents, while children whose parents were in a more vulnerable professional situation invested more in watching $T V$ and doing household chores. Children whose parents had higher education had a higher intensity of sleep, physical activity, active play, socializing online, and activity with parents, and lower intensity in household chores and school at home. Differences regarding family adversity and adaptation were found, suggesting that children from families with a negative socioeconomic change spent more time watching $T V$ and gaming/internet, and less time in sleep, socializing online, play, creative leisure, family meals, and activity with parents. In addition, children from families where daily routines changed spent more time watching $T V$, sleeping, and in an activity with parents, and less time socializing online. Children from families that presented lower adaptation levels spent more time in sleep and gaming/internet, and less time in physical activity, active play, play, family meals, and activity with parents.

Table 5 describes the correlations between the intensity of participation in daily activities, engagement levels, and child outcomes. Physical well-being was positively correlated with physical activity and active play. Psychological well-being was positively correlated with play and active play and negatively correlated with household chores and gaming/internet. Social well-being was positively correlated with the intensity of activity with parents, physical activity, active play, socializing online, and family meals. Prosocial behavior was positively correlated with active play, $T V$, play, creative leisure, family meals, household chores, and school at home. Internalizing behavior was positively correlated with household chores and negatively correlated with play. Externalizing behavior was positively correlated with gaming/internet and negatively correlated with creative leisure and play. In addition, movement activities engagement levels were positively correlated with psychological and social well-being and negatively correlated with internalizing and externalizing behaviors. Lastly, learning and socialization activities engagement levels were positively correlated with physical, psychological, and social well-being as
Table 2 Correlation Coefficients Between Movement Activities and Learning and Socialization Activities

\begin{tabular}{|c|c|c|c|c|c|c|c|c|c|c|c|c|}
\hline & 1 & 2 & 3 & 4 & 5 & 6 & 7 & 8 & 9 & 10 & 11 & 12 \\
\hline 1. sleep & - & & & & & & & & & & & \\
\hline 2. physical activity & -.02 & - & & & & & & & & & & \\
\hline 3. active play & .12 & $.54 * *$ & - & & & & & & & & & \\
\hline 4. $T V$ & .06 & .09 & -.11 & - & & & & & & & & \\
\hline 5. gaming/internet & .11 & .04 & $-.19 *$ & .19 & - & & & & & & & \\
\hline 6. socializing online & .04 & .08 & .08 & .07 & $.27 * *$ & - & & & & & & \\
\hline 7. play & -.07 & .10 & .07 & $.21 *$ & -.001 & .18 & - & & & & & \\
\hline 8. creative leisure & -.02 & -.09 & -.16 & .11 & .05 & .16 & $.32 * *$ & - & & & & \\
\hline 9. family meals & -.04 & .09 & .08 & .01 & -.16 & .11 & -.02 & $.28 * *$ & - & & & \\
\hline 10. activity $w /$ parents & .13 & $.21^{*}$ & -.002 & $.28 * *$ & .09 & .17 & $.23^{*}$ & $.35^{* *}$ & $.31 * *$ & - & & \\
\hline 11. household chores & .02 & .13 & .04 & $.31 * *$ & -.08 & .18 & $.22 *$ & $.30 * *$ & $.29 * *$ & $.30 * *$ & - & \\
\hline 12. school at home & $.19 *$ & -.01 & -.06 & .19 & -.18 & -.002 & $.21 *$ & .19 & .09 & -.01 & .14 & - \\
\hline
\end{tabular}

Statistically significant results on bold. Effect size parameters as defined by Gignac and Szodorai (2016) for $r: 0.1<\mathrm{r}<0.2$ - small, $0.2<\mathrm{r}<0.3$ - moderate, $\mathrm{r}>0.3$ - large.

$* p<.05, * * p<.01$. 
Table 3 Differences in the Intensity of Children’s Participation in Movement Activities According to Gender, Socioeconomic Characteristics, and Family Adversity and Adaptation

\begin{tabular}{|c|c|c|c|c|c|c|c|c|c|c|c|c|}
\hline \multirow{2}{*}{$\overline{\text { Gender }}$} & \multicolumn{2}{|l|}{ Sleep } & \multicolumn{2}{|c|}{ Physical activity } & \multicolumn{2}{|c|}{ Active play } & \multicolumn{2}{|l|}{$T V$} & \multicolumn{2}{|c|}{ Gaming/internet } & \multicolumn{2}{|c|}{$\begin{array}{l}\text { Socializing } \\
\text { online }\end{array}$} \\
\hline & & & & & & & & & & & & \\
\hline girls & 49.28 & 1113.50 & 44.93 & 976.50 & 43.02 & 883.00* & 57.91 & 788.50** & 50.23 & 1164.50 & 54.51 & 955.00 \\
\hline boys & 47.69 & 0.06 & 52.22 & 0.26 & 55.98 & 0.47 & 41.09 & 0.62 & 48.77 & 0.05 & 44.49 & 0.36 \\
\hline \multicolumn{13}{|l|}{ Marital status } \\
\hline married/civil union & 42.47 & 362.50 & 40.56 & 292.00 & 41.95 & 361.50 & 44.42 & 334.50 & 42.75 & 420.00 & 40.66 & $267.00 *$ \\
\hline other & 38.95 & 0.10 & 51.45 & 0.31 & 49.38 & 0.21 & 34.38 & 0.29 & 44.50 & 0.05 & 57.25 & 0.48 \\
\hline \multicolumn{13}{|l|}{ Professional status } \\
\hline employed full-time & 42.98 & 601.50 & 44.98 & 537.50 & 47.28 & 463.50* & 41.99 & 482.00 & 44.64 & 645.50 & 46.78 & 498.50 \\
\hline other & 45.34 & 0.08 & 38.29 & 0.22 & 34.39 & 0.42 & 53.63 & 0.38 & 43.97 & 0.02 & 36.24 & 0.34 \\
\hline \multicolumn{13}{|l|}{ Educational level } \\
\hline$\leq$ high-school & 39.37 & 730.00* & 40.95 & 802.50 & 41.64 & 822.50 & 47.15 & 881.00 & 43.94 & 933.00 & 41.72 & 826.50 \\
\hline higher education & 49.20 & 0.40 & 47.43 & 0.26 & 48.94 & 0.29 & 42.49 & 0.18 & 46.24 & 0.09 & 48.84 & 0.28 \\
\hline \multicolumn{13}{|l|}{ SE change } \\
\hline positive/no change & 45.97 & 784.50 & 43.17 & 846.00 & 45.18 & 925.00 & 42.92 & 820.50 & 42.99 & 824.50 & 47.04 & 823.00 \\
\hline negative change & 40.77 & 0.20 & 45.36 & 0.08 & 44.71 & 0.02 & 48.25 & 0.21 & 48.25 & 0.20 & 41.71 & 0.20 \\
\hline \multicolumn{13}{|l|}{ Daily routines } \\
\hline no change & 33.86 & 369.00 & 47.39 & 463.50 & 41.54 & 476.50 & 30.43 & 321.00* & 50.32 & 450.50 & 52.25 & 423.50 \\
\hline change & 45.95 & 0.36 & 43.35 & 0.12 & 45.65 & 0.12 & 47.72 & 0.50 & 44.01 & 0.18 & 43.65 & 0.24 \\
\hline \multicolumn{13}{|l|}{ Family adaptation } \\
\hline lower adaptation & 47.33 & 773.50 & 37.03 & $657.00 *$ & 36.33 & 638.00* & 46.39 & 878.00 & 49.73 & 768.00 & 44.45 & 906.00 \\
\hline higher adaptation & 42.06 & 0.20 & 48.05 & 0.43 & 50.11 & 0.53 & 44.18 & 0.08 & 42.21 & 0.28 & 45.32 & 0.03 \\
\hline
\end{tabular}

For each activity, the first column describes the mean ranks for each group and the second column describes the Mann-Whitney $U$ and effect size (Cohen's $d$ ). Statistically significant results on bold. Effect size parameters as defined by Gignac and Szodorai (2016), based on the conversion of $r$ to $d: 0.2<d<0.41-$ small, $0.41<d<0.63$ - moderate, $d>0.63$ - large

$\mathrm{SE}=$ Socioeconomic

$* p<.05, * * p<.01$

well as with prosocial behavior and negatively correlated with externalizing and internalizing behavior.

Table 6 describes the results from the multivariate regression models. The predictive value of each daily activity was calculated considering the contributions of the remaining daily activities in each activity domain, controlling for the effects of the covariates (i.e., gender, professional status, socioeconomic change, family adaptation). In both models, the variance explained ranged between 9\% (for psychological well-being) and 32\% (for social well-being). Higher physical well-being was predicted by higher levels of physical activity and family adaptation and lower levels of socioeconomic change, while better psychological wellbeing was predicted by higher sleep and lower household chores. Better social well-being of the child was predicted by lower socioeconomic change and higher family adaptation. In addition, higher levels of prosocial behavior were predicted by higher levels of $T V$ watching and school at home. Higher levels of internalizing behavior were predicted by lower play and socializing online, higher household chores, as well as gender (specifically, girls). Finally, higher externalizing behavior was predicted by higher gaming/internet and the professional status of the parent (other than employed full-time).

\section{Discussion}

We aimed to investigate how children spent the Covid-19 lockdown and post-lockdown period and explore its child, family, and well-being correlates. The intensity and engagement with both movement activities and learning and socialization activities were described, the factors influencing different levels of participation were investigated, and the links between participation and child well-being indicators were examined. It was observed that children's participation rates in daily activities varied significantly across child and family characteristics, and, in turn, different participation levels were linked with child outcomes. The findings of the present study are focused on the effects of daily activities on child outcomes during the pandemic, considering the contributions of different ecological factors. 
Table 4 Differences in the Intensity of Children’s Participation in Learning and Socialization Activities According to Gender, Socioeconomic Characteristics, and Family Adversity and Adaptation

\begin{tabular}{|c|c|c|c|c|c|c|c|c|c|c|c|c|}
\hline \multirow{2}{*}{$\overline{\text { Gender }}$} & \multicolumn{2}{|l|}{ Play } & \multicolumn{2}{|c|}{ Creative leisure } & \multicolumn{2}{|c|}{ Family meals } & \multicolumn{2}{|c|}{ Activity $w /$ parents } & \multicolumn{2}{|c|}{ Household chores } & \multicolumn{2}{|c|}{ School at home } \\
\hline & & & & & & & & & & & & \\
\hline girls & 56.98 & $834.00 * *$ & 53.78 & 991.00 & 46.57 & 1057.00 & 53.43 & 1008.00 & 50.58 & 1049.50 & 50.72 & 1091.50 \\
\hline boys & 42.02 & 0.55 & 45.22 & 0.30 & 50.51 & 0.14 & 45.57 & 0.28 & 46.33 & 0.15 & 47.24 & 0.12 \\
\hline \multicolumn{13}{|l|}{ Marital status } \\
\hline married/civil union & 43.18 & 424.50 & 43.21 & 422.50 & 41.04 & 327.00 & 42.02 & 366.50 & 39.73 & $232.50 *$ & 43.94 & 328.00 \\
\hline other & 41.88 & 0.04 & 41.71 & 0.04 & 48.27 & 0.20 & 48.96 & 0.20 & 56.86 & 0.50 & 33.83 & 0.29 \\
\hline \multicolumn{13}{|l|}{ Professional status } \\
\hline employed full-time & 44.89 & 628.50 & 44.96 & 624.00 & 43.84 & 613.50 & 46.07 & 547.00 & 41.19 & 482.00 & 44.41 & 618.00 \\
\hline other & 43.08 & 0.06 & 42.84 & 0.07 & 42.29 & 0.05 & 38.79 & 0.24 & 51.63 & 0.35 & 42.53 & 0.06 \\
\hline \multicolumn{13}{|l|}{ Educational level } \\
\hline$\leq$ high-school & 45.46 & 962.00 & 44.68 & 968.50 & 45.53 & 872.50 & 39.06 & 699.00* & 46.49 & 828.50 & 47.09 & 842.00 \\
\hline higher education & 44.46 & 0.04 & 45.38 & 0.03 & 42.28 & 0.13 & 51.95 & 0.51 & 41.21 & 0.21 & 41.54 & 0.22 \\
\hline \multicolumn{13}{|l|}{ SE change } \\
\hline positive/no change & 47.37 & 804.50 & 50.98 & $606.00 * *$ & 48.18 & $665.50 *$ & 49.50 & $687.50 *$ & 44.66 & 855.50 & 46.05 & 822.50 \\
\hline negative change & 41.16 & 0.24 & 35.32 & 0.62 & 37.17 & 0.43 & 37.72 & 0.49 & 42.92 & 0.07 & 41.92 & 0.16 \\
\hline \multicolumn{13}{|l|}{ Daily routines } \\
\hline no change & 39.71 & 451.00 & 46.82 & 499.50 & 38.75 & 437.50 & 37.75 & 423.50 & 45.89 & 484.50 & 45.29 & 507.00 \\
\hline change & 45.99 & 0.18 & 44.66 & 0.06 & 45.01 & 0.18 & 46.35 & 0.24 & 43.64 & 0.07 & 44.35 & 0.03 \\
\hline \multicolumn{13}{|l|}{ Family adaptation } \\
\hline lower adaptation & 40.94 & 790.00 & 43.83 & 885.50 & 39.08 & 722.50 & 40.15 & 764.00 & 43.30 & 857.50 & 44.09 & 894.00 \\
\hline higher adaptation & 47.39 & 0.24 & 45.69 & 0.07 & 46.08 & 0.30 & 47.86 & 0.29 & 44.41 & 0.04 & 44.75 & 0.03 \\
\hline
\end{tabular}

For each activity, the first column describes the mean ranks for each group and the second column describes the Mann-Whitney $U$ and effect size (Cohen's $d$ ). Statistically significant results on bold. Effect size parameters as defined by Gignac and Szodorai (2016), based on the conversion of $r$ to $d: 0.2<d<0.41-$ small, $0.41<d<0.63$ - moderate, $d>0.63$ - large.

$\mathrm{SE}=$ Socioeconomic

$* p<.05, * * p<.01$

Table 5 Correlations Between the Intensity of Participation in Daily Activities, Domain Engagement Levels, and Child Well-being Outcomes

\begin{tabular}{|c|c|c|c|c|c|c|}
\hline & $\begin{array}{l}\text { Physical } \\
\text { Well-being }\end{array}$ & $\begin{array}{l}\text { Psychological } \\
\text { Well-being }\end{array}$ & $\begin{array}{l}\text { Social } \\
\text { Well-being }\end{array}$ & $\begin{array}{l}\text { Prosocial } \\
\text { Behavior }\end{array}$ & Internalizing & Externalizing \\
\hline \multicolumn{7}{|l|}{ Movement } \\
\hline sleep & .10 & .10 & .06 & -.05 & -.001 & -.07 \\
\hline physical activity & $.27 * *$ & .09 & .17 & .03 & -.08 & -.01 \\
\hline active play & $.23 *$ & .01 & .13 & .11 & -.17 & -.07 \\
\hline$T V$ & .06 & .01 & .01 & .14 & .12 & -.05 \\
\hline gaming/internet & -.07 & -.14 & .00 & -.05 & -.04 & $.22 *$ \\
\hline socializing online & -.09 & .00 & .14 & .02 & -.15 & .05 \\
\hline engagement levels & $.25 *$ & .14 & .18 & .10 & -.15 & -.12 \\
\hline \multicolumn{7}{|c|}{$\begin{array}{l}\text { Learning and sociali- } \\
\text { zation }\end{array}$} \\
\hline play & .11 & .18 & .07 & .14 & $-.21 *$ & -.15 \\
\hline creative leisure & -.17 & .09 & -.07 & .11 & .01 & $-.23 *$ \\
\hline family meals & -.05 & -.04 & .10 & .11 & .10 & -.01 \\
\hline activity $w /$ parents & .06 & .18 & $.21 *$ & .08 & .09 & -.06 \\
\hline household chores & -.09 & $-.21 *$ & -.02 & $.21 *$ & $.25^{*}$ & .05 \\
\hline school at home & -.03 & .02 & -.03 & $.30 * *$ & .08 & -.06 \\
\hline engagement levels & $.21 *$ & $.26 *$ & $.25^{*}$ & $.21 *$ & -.18 & $-.47 * *$ \\
\hline
\end{tabular}

Statistically significant results on bold. Effect size parameters as defined by Gignac and Szodorai (2016) for $r: 0.1<\mathrm{r}<0.2$ - small, $0.2<r<0.3$-moderate, $r>0.3$ - large.

$* p<.05, * * p<.01$. 
Table 6 Multivariate Regression Models Predicting Child Well-Being Outcomes per Domain of Daily Activities and Covariates

\begin{tabular}{|c|c|c|c|c|c|c|}
\hline & $\begin{array}{l}\text { Physical } \\
\text { Well-being } \\
\beta(S E)\end{array}$ & $\begin{array}{l}\text { Psychological } \\
\text { Well-being } \\
\beta(S E)\end{array}$ & $\begin{array}{l}\text { Social } \\
\text { Well-being } \\
\beta(S E)\end{array}$ & $\begin{array}{l}\text { Prosocial } \\
\text { Behavior } \\
\beta(S E)\end{array}$ & $\begin{array}{l}\text { Internalizing } \\
\beta(S E)\end{array}$ & $\begin{array}{l}\text { Externalizing } \\
\beta(S E)\end{array}$ \\
\hline \multicolumn{7}{|l|}{ Movement } \\
\hline sleep & $.15(0.10)$ & $.21(0.11)^{*}$ & $.06(0.10)$ & $-.14(0.27)$ & $.07(0.50)$ & $-.09(0.58)$ \\
\hline physical activity & $.30(0.03)^{* *}$ & $.13(0.03)$ & $.14(0.08)$ & $-.15(0.08)$ & $.05(0.14)$ & $-.03(0.17)$ \\
\hline active play & $.04(0.02)$ & $-.11(0.02)$ & $-.07(0.02)$ & $.14(0.04)$ & $-.12(0.08)$ & $.14(0.09)$ \\
\hline$T V$ & $-.02(0.02)$ & $.05(0.02)$ & $.05(0.02)$ & $.26(0.05)^{*}$ & $.10(0.08)$ & $-.16(0.10)$ \\
\hline gaming/internet & $-.04(0.02)$ & $-.19(0.02)$ & $-.01(0.01)$ & $-.01(0.04)$ & $.03(0.08)$ & $.30(0.09)^{* *}$ \\
\hline socializing online & $-.17(0.02)$ & $.04(0.02)$ & $.03(0.02)$ & $.00(0.04)$ & $-.24(0.08)^{*}$ & $-.02(0.09)$ \\
\hline gender & $-.16(0.13)$ & $-.07(0.14)$ & $.00(0.12)$ & $.02(0.34)$ & $-.23(0.63)^{*}$ & $.02(0.73)$ \\
\hline professional status & $.12(0.17)$ & $-.09(0.18)$ & $-.12(0.15)$ & $.01(0.44)$ & $-.10(0.80)$ & $.30(0.92)^{* *}$ \\
\hline socioeconomic change & $-.14(0.10)$ & $-.03(0.10)$ & $-.23(0.09)^{*}$ & $-.10(0.25)$ & $.09(0.45)$ & $.06(0.52)$ \\
\hline family adaptation & $.20(0.14)$ & $.07(0.15)$ & $.39(0.12)^{* * *}$ & $.11(0.35)$ & $.12(0.65)$ & $-.09(0.75)$ \\
\hline $\operatorname{model} R^{2}$ & .22 & .09 & .31 & .11 & .14 & .19 \\
\hline \multicolumn{7}{|l|}{$\begin{array}{l}\text { Learning and socializa- } \\
\text { tion }\end{array}$} \\
\hline play & $.08(0.02)$ & $.11(0.02)$ & $-.03(0.02)$ & $.02(0.05)$ & $-.29(0.09) * *$ & $-.16(0.10)$ \\
\hline creative leisure & $-.19(0.02)$ & $.05(0.02)$ & $-.15(0.02)$ & $-.12(0.05)$ & $-.02(0.10)$ & $-.13(0.12)$ \\
\hline family meals & $-.03(0.03)$ & $-.02(0.03)$ & $-.01(0.02)$ & $-.01(0.07)$ & $-.06(0.12)$ & $-.00(0.15)$ \\
\hline activity $w /$ parents & $-.00(0.02)$ & $.17(0.02)$ & $.12(0.01)$ & $.04(0.04)$ & $.15(0.07)$ & $.13(0.09)$ \\
\hline household chores & $-.01(0.03)$ & $-.26(0.03) *$ & $.04(0.03)$ & $.13(0.07)$ & $.20(0.13)$ & $.04(0.16)$ \\
\hline school at home & $-.03(0.01)$ & $.03(0.01)$ & $-.01(0.01)$ & $.33(0.03)^{* * *}$ & $-.03(0.05)$ & $-.06(0.06)$ \\
\hline gender & $-.07(0.13)$ & $-.03(0.13)$ & $.00(0.11)$ & $-.04((0.31)$ & $-.28(0.57)^{* *}$ & $.08(0.70)$ \\
\hline professional status & $.09(0.17)$ & $.02(0.17)$ & $-.11(0.15)$ & $.01(0.40)$ & $-.07(0.75)$ & $.21(0.91)$ \\
\hline socioeconomic change & $-.20(0.10)$ & $-.06(0.10)$ & $-.26(0.09)^{* *}$ & $-.04(0.24)$ & $.10(0.44)$ & $.08(0.54)$ \\
\hline family adaptation & $.21(0.14)^{*}$ & $.06(0.14)$ & $.37(0.12)^{* * * *}$ & $.13(0.34)$ & $.12(0.63)$ & $-.13(0.76)$ \\
\hline model $R^{2}$ & .12 & .11 & .32 & .16 & .18 & .15 \\
\hline
\end{tabular}

Values are standardized beta coefficients and standard errors; statistically significant results on bold; $* p<.05, * * p<.01, * * * p<.001$.

Control variables $=$ gender, professional status, socioeconomic change, and family adaptation (all dichotomic).

Regarding children's participation in daily activities, our findings indicated a higher prevalence of sedentary behaviors (e.g., screen-time) and a lower prevalence of active leisure and playing activities. Recently, studies have confirmed this pandemic-related change characterized by a decline in physical activities and play and an increase in sedentary behaviors (i.e., screen-based activities) linked with a decrease in the proportion of children meeting the recommended guidelines for combined movement behaviors (Bates et al., 2020; Dunton et al., 2020; Guan et al., 2020; Moore et al., 2020; Pombo et al., 2021). A higher intensity of sedentary behaviors, particularly screen-time, coupled with lower levels of physical movement and stimulating activities (i.e., play, creative leisure, active play) may constitute a risk for the physical and mental well-being of children (Bates et al., 2020; Berntsson \& Ringsberg, 2014; Kremer et al., 2014; Tsiros et al., 2017). These findings indicate that the pandemic mitigation efforts might have had unfavorable collateral effects on child well-being and worsened pre-existing problems related to sedentary lifestyles (Pombo et al., 2021). Noteworthy, in the present study, children have shown higher motivation and interest when participating in active play and physical activities in their homes and communities. Our findings indicate that children's positive engagement with an activity is an important predictor of individual participation in healthy activities, also predicting better levels of well-being. Social restrictions and the "stay at home" advice could have been balanced with a health promotion message directed at children and their parents (Moore et al., 2020).

Concerning the factors that influenced different participation levels in daily activities, boys exhibited a more active profile while girls presented a playing- and socializing-oriented profile. This is in line with recent studies that have reported that during the lockdown girls were more physically inactive and engaged more in social activities than boys (Dunton et al., 2020; Guerrero et al., 2020; Moore et al., 2020). On the one hand, girls may be at higher risk as a result of spending less time in active leisure; on the other 
hand, they could develop new skills and coping mechanisms in a time of crisis as they were more involved in learning and socialization experiences, as compared to boys. However, in our study, we found that girls showed higher levels of internalizing behaviors, and this constitutes a risk for child well-being worthy of further attention. To be effective, interventions should target these gendered differences. Our findings also suggest that children whose families were in a more vulnerable situation during this period (e.g., lower socioeconomic status, family adversity, lower adaptation) exhibited a more sedentary/low-stimulation profile characterized by lower levels of active leisure, decreased playing and socializing activities, and higher screen time. Besides constituting a disadvantage in a healthy adaptation to the sanitary crisis, these differences indicate that the pandemic's impact was not equal for all children. These findings may reflect preexisting differences and are in line with previous research on social inequalities and health behaviors (Currie et al., 2012; Inchley \& Currie, 2016), thus corroborating the existence of health and developmental disparities between social groups during the pandemic (González et al., 2020; Guerrero et al., 2020; Moore et al., 2020). Therefore, it is crucial to call for effective interventions that promote healthy routines and lifestyles and, particularly, support families with lower internal and external resources in the protection of their children's well-being.

Regarding the effects of daily activities on child outcomes, correlation results indicated that playing and learning activities were linked to lower behavioral problems, active leisure was positively associated with physical well-being, and socialization and family activities were linked to better social well-being. However, these associations are complex and other ecological factors may have influenced the links between time use and child outcomes. Findings from the regression models, that considered the different effects of daily activities while controlling for important covariates, provided a more fine-grained view of this relationship. Overall, findings indicated that sleep, active leisure, and family adaptation strategies contributed positively to the physical and psychological well-being of the child and playing and socializing activities, as well as gender (i.e., boys), predicted lower levels of internalizing behaviors. Noteworthy, lower levels of experienced socioeconomic adversity and higher levels of adaptation strategies from families were particularly linked to better social well-being. Also, screen time activities showed distinct effects on child outcomes: watching TV predicted better prosocial behavior and socializing online predicted lower internalizing behaviors, however, gaming/internet was linked to higher externalizing behaviors. In addition, household chores predicted lower psychological well-being and higher internalizing behaviors, and a more vulnerable professional status of the parent was linked to externalizing behaviors. As expected, a few daily activities (e.g., activity with parent) lost their predictive value when controlling for the effects of other activities and factors. Although the magnitude of these associations was small to moderate, it is consistent with previous studies that reported the positive effects of playing, learning, and socializing activities (Crosnoe \& Trinitapoli, 2008; Lam et al., 2012; McHale et al., 2001), and the negative effects of household chores and screen time (Kremer et al., 2014; Lam et al., 2016; Tsiros et al., 2017). Patterns of daily activities characterized by frequent physical activity, low sedentary behavior, and higher involvement with stimulating activities (i.e., playing, socializing, productive/active leisure) have been consistently associated with better health and quality of life in children (Berntsson \& Rinsberg, 2014; Wong et al., 2017). Also, factors such as the experienced socioeconomic adversity and the families' coping strategies emerged as significant predictors of child well-being and should be considered as targets of effective interventions.

Furthermore, parents' ability to adjust family routines and activities to children's needs amid adverse environmental constraints and adversity is crucial (Moore et al., 2020). Engaging in activities with parents was associated with higher participation rates in other relevant activities (e.g., play, physical activity, creative leisure, meals). Children from families with higher levels of adaptation effectively showed healthier activity patterns, with implications for their well-being. It suggests distinct family coping strategies but also the active role of parents in supporting their children's participation in positive patterns of activities (Berntsson \& Ringsberg, 2014; Lam \& McHale, 2015; Lam et al., 2012; Moore et al., 2020). Indeed, Guerrero et al. (2020) have found that parental perceived ability to support and guide child activities is a good predictor of children meeting movement activity guidelines, and Moore et al. (2020) have highlighted that parental co-participation is an essential factor in the promotion of healthier activity patterns. For example, children whose families reported a relevant change in their daily routines spent more time watching television, sleeping, and in activities with parents, suggesting that this might have been an adaptation strategy for a significant proportion of families during the lockdown. In addition, as a mitigation effort during this period, children attended school lessons through a home-based distance-learning model. Expectedly, a significant proportion of families have used these available educational resources, observable by the high intensity of television viewing and studying at home activities (encompassing television lessons, interactions with teachers, and homework), which may have contributed to the additional screen time observed (Dunton et al., 2020). The investment in these activities reveals families' different strategies implemented to adjust to school closures and maintain a predictable and structured routine. For other families, this might have been a way to balance their lower access to educational 
resources in a context where learning gaps became notorious (see Van Lancker \& Parolin, 2020). Time dedicated to school activities (via television and other platforms) might have helped improve children's academic competence and prevent learning loss; however, this could have happened at the cost of other important activities such as sleep, physical activity, or family leisure (see Zhang et al., 2017). Time invested in academic activities has been linked to better competence but also higher stress and poorer mental health in children (Brown et al., 2011; Zhang et al., 2017). Conversely, a constructive use of social and dyadic time with parents has been associated with better competence and psychosocial adjustment (Crosnoe \& Trinitapoli, 2008; Lam et al., 2012; McHale et al., 2001), thus constituting an asset for children during the pandemic.

The identification of these different participation profiles linked to child and family characteristics and child outcomes may help detect well-being risks and identify promising avenues for future effective intervention strategies. In general, our study indicates the need to improve the knowledge on the effects of different patterns of daily activities on children's well-being and adjustment during a health and social crisis and its underlying mechanisms. The magnitude of the impact of social isolation and school closures on child well-being is still emerging (Larsen, 2021). Our findings suggest an important avenue for promoting child well-being: the regulation of daily activity patterns by intervention strategies that bring together child, family, school, and community efforts (see Wong et al., 2017). There is a need to assess effective strategies, at the family and community levels, that facilitate the substitution of sedentary leisure for active and stimulating leisure pursuits. These strategies should promote predictable daily routines and facilitate higher investment in stimulating activities and family quality time, particularly among those who are socially vulnerable (Moore et al., 2020; Pombo et al., 2021). These efforts may be challenging in the context of social isolation, uncertainty, and disruption of families` everyday lives; however, small effective changes could protect and promote child well-being in the present and future (Bates et al., 2020). Here, parental coparticipation and the ability to creatively influence children's daily activities are crucial elements. Noteworthy, children's engagement with activities was indicative of better overall well-being. This bidirectional relationship also suggests the importance of positively involving and motivating children for participating in positive and constructive activities, thus enhancing the health and developmental gains of those activities. Finally, several recommendations warranting immediate action to protect children, especially vulnerable ones, from the downside of the pandemic have been issued and constitute a valuable resource for professionals and policymakers, but also for families and communities (see Guan et al., 2020; Margaritis et al., 2020; Miranda et al., 2020; Prime et al., 2020; Shah et al., 2020; Wang et al., 2020).

The present study has several limitations. First, the study design and sampling do not allow for the generalization of our findings and impede the inference of causality. For example, the distribution of parents' professional and educational status was higher in our sample than in the population, which may have biased the results (e.g., the underrepresentation of low-income families may hinder the negative impacts of the pandemic). Second, missing values, social desirability, and recall bias (i.e., self-report) may have influenced our findings. Third, we have not controlled for the increase of the familywise error rate across our results, but we have used a robust approach that included the calculation of $95 \%$ CIs for $p$-values coupled with a focus on the description of effect sizes. Nonetheless, the findings presented here are generally in line with recent literature, and the use of bootstrapping procedures and multivariate regression models strengthened their validity. In addition, we have presented a multidimensional assessment of child well-being outcomes and included a wide range of daily activities that better portray children's everyday lives during the pandemic, and to our knowledge, this is one of the few studies to do so.

\section{Conclusion}

This study provided an outlook on how children spent the Covid-19 lockdown and post-lockdown period and explored its child, family, and well-being correlates. Risks for child well-being were found regarding sedentary and low-stimulation profiles, particularly in socially vulnerable children, but also protective factors regarding active, stimulating, and adaptive family behaviors; thus, opportunities for intervention were identified. A deeper understanding of the effects of daily activities on child outcomes and its ecological correlates could guide intervention studies on the most effective ways to protect child well-being and development in the present and future crises.

Authors' contributions All authors contributed to the study conception and design. Data analysis and interpretation was performed by Vitor Hugo Oliveira. The first draft of the manuscript was written by Vitor Hugo Oliveira and Paula Cristina Martins and Graça Simões Carvalho commented on previous versions of the manuscript and critically revised the work. All authors read and approved the final manuscript.

Funding This work was financially supported through the Foundation for Science and Technology by Portuguese national funds of the MCTES and by European funds of the POCH (European Social Fund), within the framework of the CIEC - Research Centre on Child Studies of the University of Minho, project under the reference UID/ CED/00317/2019, and a PhD scholarship under the reference SFRH/ $\mathrm{BD} / 135674 / 2018$. 
Data availability Not applicable.

Code availability Not applicable.

\section{Declarations}

Conflicts of interest The authors declare that have no conflicts of interest.

Additional declarations for articles in life science journals that report the results of studies involving humans and/or animals Not applicable

Ethics approval This study was approved by the University of Minho Ethics Committee and the National Ministry of Education and is in accordance with the 1964 Helsinki declaration and its later amendments or comparable ethical standards.

Consent to participate Informed consent and assent were obtained from parents and children involved in the study.

Consent for publication The authors have approved this manuscript and authorship order. This manuscript has not been published and it is not under consideration for publication elsewhere. There is not any related or redundant paper published or submitted for publication.

\section{References}

Bates, L. C., Zieff, G., Stanford, K., Moore, J. B., Kerr, Z. Y., Hanson, E. D., Gibbs, B. B., Kline, C. E., \& Stoner, L. (2020). COVID19 impact on behaviors across the 24-hour day in children and adolescents: Physical activity, sedentary behavior, and sleep. Children, 7(9), 138. https://doi.org/10.3390/children7090138

Berntsson, L., \& Ringsberg, K. (2014). Swedish parents' activities together with their children and children's health: A study of children aged 2-17 years. Scandinavian Journal of Public Health, 42, 41-51. https://doi.org/10.1177/1403494814544901

Brown, S. L., Nobiling, B. D., Teufel, J., \& Birch, D. A. (2011). Are kids too busy? Early adolescents' perceptions of discretionary activities, overscheduling, and stress. Journal of School Health, 81(9), 574-580. https://doi.org/10.1111/j.1746-1561.2011. 00629.x

Carson, V., Hunter, S., Kuzik, N., Gray, C. E., Poitras, V. J., Chaput, J. P., Saunders, T. J., Katzmarzyk, P. T., Okely, A. D., Gorber, S. C., Kho, M. E., Sampson, M., Lee, H., \& Tremblay, M. S. (2016). Systematic review of sedentary behaviour and health indicators in school-aged children and youth: An update. Applied Physiology, Nutrition and Metabolism, 41(6), 240-265. https://doi.org/ 10.1139/apnm-2015-0630

Cheng, T. L., Moon, M., \& Artman, M. (2020). Shoring up the safety net for children in the COVID-19 pandemic. Pediatric Research, 88(3), 349-351. https://doi.org/10.1038/s41390-020-1071-7

Cluver, L., Lachman, J. M., Sherr, L., Wessels, I., Krug, E., Rakotomalala, S., Blight, S., Hillis, S., Bachman, G., Green, O., Butchart, A., Tomlinson, M., Ward, C. L., Doubt, J., \& McDonald, K. (2020). Parenting in a time of COVID-19. The Lancet, 395(10231), E64. https://doi.org/10.1016/S0140-6736(20) 30736-4

Crosnoe, R., \& Trinitapoli, J. (2008). Shared family activities and the transition from childhood into adolescence. Journal of Research on Adolescence, 18(1), 23-48. https://doi.org/10.1111/j.15327795.2008.00549.x
Currie, C., Zanotti, C., Morgan, A., Currie, D., de Looze, M., Roberts, C., et al. (2012). Social determinants of health and well-being among young people. Health Behaviour in School-aged Children (HBSC) study: International report from the 2009/2010 survey (Report No.6). World Health Organisation. https://www.euro.who. int/en/publications/abstracts/social-determinants-of-health-andwell-being-among-young-people.-health-behaviour-in-schoolaged-children-hbsc-study

Dale, L. P., Vanderloo, L., Moore, S., \& Faulkner, G. (2019). Physical activity and depression, anxiety, and self-esteem in children and youth: An umbrella systematic review. Mental Health and Physical Activity, 16, 66-79. https://doi.org/10.1016/j.mhpa.2018.12. 001

Dunton, G. F., Do, B., \& Wang, S. D. (2020). Early effects of the COVID-19 pandemic on physical activity and sedentary behavior in children living in the U.S. BMC Public Health, 20(1), 1351. https://doi.org/10.1186/s12889-020-09429-3

Fegert, J. M., Vitiello, B., Plener, P. L., \& Clemens, V. (2020). Challenges and burden of the Coronavirus 2019 (COVID-19) pandemic for child and adolescent mental health: A narrative review to highlight clinical and research needs in the acute phase and the long return to normality. Child and Adolescent Psychiatry and Mental Health, 14, 20. https://doi.org/10.1186/s13034-020-00329-3

Fore, H. H. (2020). A wake-up call: COVID-19 and its impact on children's health and wellbeing. The Lancet Global Health, 8(7), E861-E862. https://doi.org/10.1016/S2214-109X(20)30238-2

Gignac, G. E., \& Szodorai, E. T. (2016). Effect size guidelines for individual differences researchers. Personality and individual differences, 102, 74-78. https://doi.org/10.1016/j.paid.2016.06.069

Goodman, R. (2001). Psychometric properties of the strengths and difficulties questionnaire. Journal of the American Academy of Child and Adolescent Psychiatry, 40(11), 1337-1345. https://doi. org/10.1097/00004583-200111000-00015

Guan, H., Okely, A. D., Aguilar-Farias, N., del Pozo Cruz, B., Draper, C. E., El Hamdouchi, A., Florindo, A. A., Jáuregui, A., Katzmarzyk, P. T., Kontsevaya, A., Löf, M., Park, W., Reilly, J. J., Sharma, D., Tremblay, M. S., \& Veldman, S. L. C. (2020). Promoting healthy movement behaviours among children during the COVID-19 pandemic. The Lancet Child and Adolescent Health, 4(6), 416-418. https://doi.org/10.1016/S2352-4642(20)30131-0

Guerrero, M. D., Vanderloo, L. M., Rhodes, R. E., Faulkner, G., Moore, S. A., \& Tremblay, M. S. (2020). Canadian children's and youth's adherence to the 24-h movement guidelines during the COVID-19 pandemic: A decision tree analysis. Journal of Sport and Health Science, 9(4), 313-321. https://doi.org/10.1016/j.jshs.2020.06.005

González, C. T., Aldana, G. M., León, I. A., López, L. A., Núñez, D. N., \& Gutiérrez, Y. I. (2020). COVID-19 voluntary social isolation and its effects in sociofamily and children's behavior. Salud Mental, 43(6). https://doi.org/10.17711/SM.0185-3325.2020.036

Inchley, J., \& Currie, D. (2016). Growing up unequal: gender and socioeconomic differences in young people's health and wellbeing. Health Behaviour in School-aged Children (HBSC) study: international report from the 2013/2014 survey (Report No.7). World Health Organization. https://www.euro.who.int/_data/ assets/pdf_file/0003/303438/HSBC-No.7-Growing-up-unequalFull-Report.pdf

Kremer, P., Elshaug, C., Leslie, E., Toumbourou, J. W., Patton, G. C., \& Williams, J. (2014). Physical activity, leisure-time screen use and depression among children and young adolescents. Journal of Science and Medicine in Sport, 17(2), 183-187. https://doi.org/ 10.1016/j.jsams.2013.03.012

Lam, C. B., \& McHale, S. M. (2015). Time use as cause and consequence of youth development. Child Development Perspectives, 9(1), 20-25. https://doi.org/10.1111/cdep.12100

Lam, C. B., Greene, K. M., \& McHale, S. M. (2016). Housework time from middle childhood through adolescence: Links to parental 
work hours and youth adjustment. Developmental psychology, 52(12), 2071-2084. https://doi.org/10.1037/dev0000223

Lam, C. B., McHale, S. M., \& Crouter, A. C. (2012). Parent-child shared time from middle childhood to late adolescence: Developmental course and adjustment correlates. Child Development, 83(6), 2089-2103. https://doi.org/10.1111/j.1467-8624.2012. 01826.x

Larsen, L., Helland, M. S., \& Holt, T. (2021). The impact of school closure and social isolation on children in vulnerable families during COVID-19: a focus on children's reactions. European child \& adolescent psychiatry, 1-11. https://doi.org/10.1007/ s00787-021-01758-x

Loades, M. E., Chatburn, E., Higson-Sweeney, N., Reynolds, S., Shafran, R., Brigden, A., Linney, C., McManus, M. N., Borwick, C., \& Crawley, E. (2020). Rapid systematic review: The impact of social isolation and lneliness on the mental health of children and adolescents in the context of COVID-19. Journal of the American Academy of Child and Adolescent Psychiatry, 59(11), 1218-1239. https://doi.org/10.1016/j.jaac.2020.05.009

Margaritis, I., Houdart, S., El Ouadrhiri, Y., Bigard, X., Vuillemin, A., \& Duché, P. (2020). How to deal with COVID-19 epidemicrelated lockdown physical inactivity and sedentary increase in youth? Adaptation of Anses' benchmarks. Archives of Public Health, 78, 1-6. https://doi.org/10.1186/s13690-020-00432-z

Metsäpelto, R. L., \& Pulkkinen, L. (2014). The benefits of extracurricular activities for socioemotional behavior and school achievement in middle childhood: An overview of the research. Journal for educational research online, 6(3), 10-33.

McHale, S. M., Crouter, A. C., \& Tucker, C. J. (2001). Free-time activities in middle childhood: Links with adjustment in early adolescence. Child Development, 72(6), 1764-1778. https://doi.org/10. 1111/1467-8624.00377

Miranda, D. M., Athanasio, B., Oliveira, A. C., \& Silva, A. C. S. (2020). How is COVID-19 pandemic impacting mental health of children and adolescents? International Journal of Disaster Risk Reduction, 51, 101845. https://doi.org/10.1016/j.ijdrr.2020. 101845

Moore, S. A., Faulkner, G., Rhodes, R. E., Brussoni, M., ChulakBozzer, T., Ferguson, L. J., Mitra, R., O’Reilly, N., Spence, J. C., Vanderloo, L. M., \& Tremblay, M. S. (2020). Impact of the COVID-19 virus outbreak on movement and play behaviours of Canadian children and youth: A national survey. International Journal of Behavioral Nutrition and Physical Activity, 17(1), 85. https://doi.org/10.1186/s12966-020-00987-8

Oberle, E., Ji, X. R., Magee, C., Guhn, M., Schonert-Reichl, K. A., \& Gadermann, A. M. (2019). Extracurricular activity profiles and wellbeing in middle childhood: A population-level study. PLoS ONE, 14(7), 1-16. https://doi.org/10.1371/journal.pone.0218488

Oliveira, V. H., Martins, P. C., \& Carvalho, G. S. (2019). Q25 - Questionário das 25 Atividades Quotidianas da Criança [Measurement instrument]. Unpublished instrument.

Patrick, S. W., Henkhaus, L. E., Zickafoose, J. S., Lovell, K., Halvorson, A., Loch, S., Letterie, M., \& Davis, M. M. (2020). Wellbeing of parents and children during the COVID-19 pandemic: A national survey. Pediatrics, 146(4), e2020016824. https://doi.org/ 10.1542/peds.2020-016824

Pombo, A., Luz, C., Rodrigues, L. P., \& Cordovil, R. (2021). Effects of COVID-19 confinement on the household routines of children in Portugal. Journal of Child and Family Studies, 30, 1664-1674. https://doi.org/10.1007/s10826-021-01961-z

Prime, H., Wade, M., \& Browne, D. T. (2020). Risk and resilience in family well-being during the COVID-19 pandemic. American Psychologist., 75(5), 631-643. https://doi.org/10.1037/amp00 00660631

Ravens-Sieberer, U., Auquier, P., Erhart, M., Gosch, A., Rajmil, L., Bruil, J., Power, M., Duer, W., Cloetta, B., Czemy, L., Mazur, J., Czimbalmos, A., Tountas, Y., Hagquist, C., Kilroe, J., \& the European KIDSCREEN Group. (2007). The KIDSCREEN-27 quality of life measure for children and adolescents: Psychometric results from a cross-cultural survey in 13 European countries. Quality of Life Research, 16(8), 1347-1356. https://doi.org/10. 1007/s11136-007-9240-2

Ruscio, J. (2008). Constructing confidence intervals for Spearman's rank correlation with ordinal data: a simulation study comparing analytic and bootstrap methods. Journal of Modern Applied Statistical Methods, 7(2), 416-434. https://doi.org/10.22237/jmasm/ 1225512360

Shah, K., Mann, S., Singh, R., Bangar, R., \& Kulkarni, R. (2020). Impact of COVID-19 on the mental health of children and adolescents. Cureus, 12(8). https://doi.org/10.7759/cureus.10051

Tsiros, M. D., Samaras, M. G., Coates, A. M., \& Olds, T. (2017). Useof-time and health-related quality of life in 10- to 13-year-old children: not all screen time or physical activity minutes are the same. Quality of Life Research, 26(11), 3119-3129. https://doi. org/10.1007/s11136-017-1639-9

United Nations. (2020). Policy Brief: The Impact of COVID-19 on children. https://unsdg.un.org/resources/policy-brief-impactcovid-19-children

Van Lancker, W., \& Parolin, Z. (2020). COVID-19, school closures, and child poverty: a social crisis in the making. The Lancet Public Health, 5(5), 243-244. https://doi.org/10.1016/S2468-2667(20) 30084-0

Wang, G., Zhang, Y., Zhao, J., Zhang, J., \& Jiang, F. (2020). Mitigate the effects of home confinement on children during the COVID-19 outbreak. The Lancet, 325(10228), 945-947. https://doi.org/10. 1016/S0140-6736(20)30547-X

Wong, M., Lycett, K., Olds, T., Gold, L., \& Wake, M. (2017). Use of time and adolescent health-related quality of life/well-being: A scoping review. Acta Paediatrica, 106(8), 1239-1245. https://doi. org/10.1111/apa.13929

Yogman, M., Garner, A., Hutchinson, J., Hirsh-Pasek, K., Golinkoff, R. M., Baum, R., \& Wissow, L. (2018). The power of play: A pediatric role in enhancing development in young children. Pediatrics, 142(3). https://doi.org/10.1542/peds.2018-2058

Zhang, Y., Zhang, D., Li, X., Ip, P., Ho, F., Jiang, Y., Sun, W., Zhu, Q., Zhu, W., Zhang, J., Zhao, H., Wang, G., Shen, X., \& Jiang, F. (2017). Daily time-use patterns and obesity and mental health among primary school students in shanghai: A population-based cross-sectional study. Scientific Reports, 7(1), 16200. https://doi. org/10.1038/s41598-017-15102-4

Publisher's Note Springer Nature remains neutral with regard to jurisdictional claims in published maps and institutional affiliations. 